Ferris, F. S. \& Banda, F. (2015). "Poof! a'm heppily saving the Lord...": multimodality and evaluative discourses in male toilet graffiti at the University of the Western Cape. African

\title{
"Poof! a'm heppily saving the Lord...": multimodality and evaluative discourses in male toilet graffiti at the University of the Western Cape
}

Fiona S. Ferris and Felix Banda

\begin{abstract}
This paper explores the use of punctuation, capitalisation, linguistic forms and images in the construction of evaluative discourses in male toilet graffiti at the University of the Western Cape. Of particular interest is how male students use these devises in the discursive construction of the appraisal resource of Attitude, Graduation and Evaluation. Using over 150 tokens of graffiti, the paper uses a multimodal approach employing notions of resemiotisation and remediation to show how taboo language, font size, images and sketches are repurposed to aid the evaluation of the 'self' and the 'other' in toilet graffiti. The paper shows that through utilising multimodal texts, graffiti writers are able to reformulate and situate novel meanings in contexts; and in terms of appraisal, the verbal and non-verbal semiotic material are strategically combined to engender novel evaluations.
\end{abstract}

\section{Introduction}

Toilet graffiti as a literacy practice, although a very common sight, is still largely neglected in academic literature. A study by Gebhard, Kinsey, Martin, and Pomeroy (1953) on toilet graffiti and sexual desire sparked some academic interest in this area. A few theorists have thus far written short articles on toilet graffiti, but comprehensive research on toilet graffiti as a literacy practice in area of communication and media studies still lacks. The few research articles that do exist are from the disciplines of Sociology, Psychology and Anthropology. These studies are usually focused on the amount of toilet graffiti written, graffiti and sexual references, gendered differences in toilet graffiti or the arising themes (Wales \& Brewer, 1976; Dundes, 1966; Farr \& Gordon, 1975; Farnia, 2014; Flores \& Sechrest, 1969; Gebhard et al., 1953; Lomas, 1973; Olowu, 1983; Pennebaker \& Sanders, 1976; Wolff, 2010 etc.). In the field of communication, limited research exist on graffiti on the level of semantics and as a genre (Adams \& Winter, 1997; Green, 2003). Bates and Martin (1980, p. 30) assert that very little has been written on toilet graffiti in terms of its content or the characteristics of the people who write them. Ferris (2010) laments that in South Africa there is even a bigger dearth of studies on graffiti focusing on students writing on toilet walls. Contextappropriate literature is therefore not available for toilet graffiti in South Africa. 


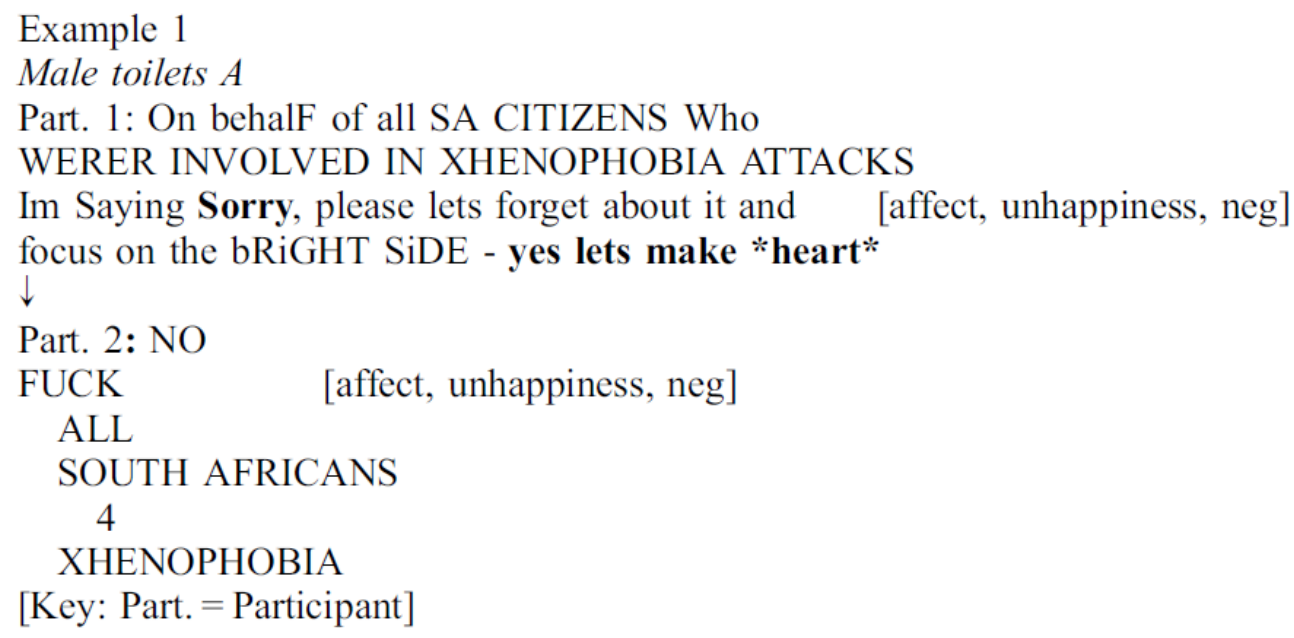

As a result of the dearth of literature on these literacies, and the important alternative medium of communication the toilet constitutes, an investigation of toilet graffiti is vital.

Secondly, Appraisal theory is a fairly new development in the area of Systemic Functional Linguistics. Moreover, it is one of the "least understood and most underresearched areas in linguistics ...' (Eggins \& Slade, 1997, p. 124). Not much has changed in recent years with regard to the abovementioned statement. Although Appraisal theory was developed for the analysis of lexical items, few attempts exist to expand the theory to include non-lexical items. Bock (2011) argues that Appraisal theory needs to consider code-switching as a resource that is available to multilingual speakers in their evaluative discourse. She uses TRC data to show how anti-apartheid activists in their testimonies would switch between the formal and local versions of Afrikaans to color their evaluations. The focus on evaluative uses of language (Martin \& White, 2005) neglects multimodal/multisemiotic resources that are equally important, and in any case, used in concert with verbal elements. With regard to this shortfall, only Economou (2009) attempted to extend the Appraisal framework to visual designs. He developed a system of visual appraisal by applying the appraisal options to news photos to build a system which was later applied alongside the system created for lexical choices to cater for the multimodal texts.

The present paper illustrates how male students use pictures, sketches, punctuation and capitalisation together with taboo language to aid appraisal resources in toilet graffiti. In the process, we intend to show that these multisemiotic resources function as graduation elements and as written intonation of affect, appreciation and judgement. In turn, we argue that these semiotic choices provide insights into writer evaluations of stories, stances and attitudes to topical issues in vogue in time and space.

\section{Context}

The study is based at the University of the Western Cape which opened in 1959, enrolling its first students in 1960 as the University College of the Western Cape. The University College of the Western Cape was designed to provide human resources for the needs of 'coloured' (mixed race) people as defined by the Apartheid state. This entailed providing 'coloureds' limited training for lower to middle-level positions in 
education, the civil service and other institutions designed to serve a separated 'coloured' community, thus strategically enforcing racial divides (Wolpe, 1995, p. 280).

\author{
Example 2 \\ Male toilets $A$ \\ Part. 1: ZUMA is our President \\ NOW nothing we can do \\ will change that ... \\ Part. 2: I HATE \\ JZ ONLY ... \\ [affect, dissatisfaction, neg] \\ [affect, unhappiness, neg]
}

We are mindful that the designation 'coloured' as a racial or demographic category is contentious, with some labelled as such and as handed down from the apartheid discourses, claim different identities.

As Lalu and Murray (2012) and Cooper and Subotsky (2001) note, UWC is renowned across international borders for a number of reasons: (a) its active role in the movement towards a democratic South Africa, (b) the introduction of an open policy to education and (c) its major role in promoting diversity in higher education. This study indicates that UWC is still an active site for identity construction and deconstruction especially in the context of racial, cultural and political debates.

\title{
Towards a multimodal approach to the language of evaluation
}

This paper is informed by appraisal theory, from the Systemic Functional approach, which systematically examines the appraisals performed (Martin \& White, 2005). This will be supplemented by notions of resemiotisation and semiotic remediation (Iedema, 2003; Prior \& Hengst, 2010).

\section{Appraisal theory}

Appraisal theory as it is used in this paper is concerned with the interpersonal meanings of participants in terms of their attitudinal evaluations of phenomena. It encompasses all evaluative uses of language (Vandenbergen, 2008). This approach is used to explore, describe and explain the manner in which language is used to evaluate, to adopt a stance, to construct textual personae and to manage interpersonal relationships and positioning (Martin \& White, 2005, pp. 40, 92). In sum, it explores the overt expression of Attitudes: judgements and affect, and emotive responses generally and how they may be more indirectly implied, presupposed or assumed'. The declaration of attitude is viewed as dialogic, in that it is directed towards 'aligning the addressee into a community of shared values and beliefs' (Martin \& White, 2005, p. 95). Instances of appraisal simultaneously express three kinds of meanings according to Bock (2011): these include 'different kinds of attitudes (attitudes); how intensely these attitudes are felt (graduation); and where these different attitudes come from (engagement)' (Bock, 2011, pp. 3-4). The three main resources for the realization of these meanings in the appraisal framework is Attitude, Graduation and Engagement, which are differentiated by semantics rather than grammatical features according to Martin and White (2005). 


\section{Attitude}

In doing an attitudinal analysis, one is interested in the language speakers/writers use to assess things, state affairs and talk about people, places and happenings in a positive or negative manner by referring to their emotional states or 'systems of culturally determined value systems'. ${ }^{1}$

\section{Example 3}

Male toilets $A$

Part. 1: Fuck all you fuckin hot***

Part. 2: Fuck you "coloureds"

[affect, unhappiness, neg]

[affect, unhappiness, neg]

\& your fucken!

Mother

Part. 3: Fuck coloureds! [affect, unhappiness, neg]

These semantic regions depicting manifestations of Attitude are sub-divided into affect, judgement and appreciation.

\section{Affect}

The evaluation of emotion, or how something or someone makes someone feel, is referred to as affect (Eggins \& Slade, 1997, p. 129). The expression of affect can be from the evaluator's stance or a report on someone else's feelings. This sub-system of attitude usually answers the question 'How do/did you feel about it?'(Eggins \& Slade, 1997, p. 129). Appraisals dealing with affect usually occur in polar pairs in which one is positive and the other negative (Eggins \& Slade, 1997, p. 29; Martin \& White, 2005, p. 46).

Appraisals of emotions are dealt with in terms of three dimensions. The happiness/ unhappiness dimension incorporates feelings to do with 'affairs of the heart' such as sadness, hate, happiness, anger and love (Bock, 2007, p. 78). The second dimension, security/insecurity of affect, 'covers emotions concerned with ecosocial wellbeing, anxiety, fear, confidence, trust' (Bock, 2007, p. 78). Lastly, the satisfaction/ dissatisfaction dimension of affect covers emotions that involve our feelings of frustration and achievement relating to our involving activities, which consist of both our roles as spectators and participants (Martin \& White, 2005, p. 50). These emotional dispositions are realised differently in sentences (as a quality, process and a comment), according to Martin and White (2005, p. 46). They are also the basis on which one makes judgements on emotions, behaviors and things.

\section{Judgement}

Judgement refers to the assessment of actions or behaviours of people (Iedema, Feez \& White, 1994, p. 1; Martin \& White, 2005, p. 59) and is made in terms of determined societal norms, ethics and morality of people (Eggins \& Slade, 1997, p. 125; Iedema et al., 1994, p. 1). Judgements provide the reader with an insight into the writer's (participant's) stance towards the behaviors of the evaluated, and can be identified by asking the questions: 'How would you judge that behavior?' and 'What do you/did you think of that?' (Eggins \& Slade, 1997, p. 130). 
Two forms of judgements occur in appraisal theory: judgement of social esteem and judgement of social sanction. Judgement of social esteem deals with the manner in which people's behaviour corresponds to socially desirable standards (Eggins \& Slade, 1997, p. 125). Judgement of social esteem is subdivided into three subcategories; these are normality, referring to how special something is; capacity, indicating how capable somebody's actions are; and tenacity, which evaluates how dependable someone's behaviour is (Martin \& White, 2005, p. 53).

\author{
Example 4 \\ Part. 2: You kick knowledge, real tak. Right here! [judgement, veracity, pos] \\ $\uparrow$ \\ Part. 1: BLACK/COLOURED NATIONS ARE CONSUMPTIVE NATIONS- LOOK \\ AROUND AND ASK YOURSELF WHAT THEY MADE AROUND YOU. IF NOTHING \\ START TO CHANGE THAT AND STOP WRITING TOILET WALLS INSTEAD OF \\ CHANGING YOUR SITUATION \\ I'M NOT FIGHTING I'M JST SUGGESTING! [judgement, capacity, neg] \\ Part. 3: SEE WHO'S speaking NoT WRiTiNG WALLS [judgement, propriety, neg]
}

Judgement of social sanction, on the other hand, comprises veracity, which deals with the truth-value of behaviours and propriety that evaluates the ethics involved in behaviours (Martin \& White, 2005, p. 53).

\title{
Appreciation
}

Appreciation is the evaluation of objects, processes and natural affairs including abstract things such as relationships or quality of life. An important distinction between appreciation and judgement is that judgement targets the behaviours of participants, whereas the target of appreciation is things (Bock, 2007, p. 80).

Appreciation can be realised in three categories: reaction, composition and valuation. Martin and White sum this up when they say that appreciations can be divided into our 'reactions' to things (do they catch our attention; do they please us?), which is further categorised in terms of their impact and quality, their 'composition' (balance and complexity) and their 'value' (how innovative, authentic, timely, etc.). (Martin \&White, 2005, p. 56) Whereas we appreciate the importance of verbal language, we also want to recognise the importance of non-verbal language in the manifestations and consumption of Attitude (affect, judgement and appreciation). At the very least, nonverbal semiotics aid in fine-tuning appraisal resources as will be shown in this paper.

\section{Graduation}

Graduation deals with the grading of phenomena whereby feelings can either be amplified and categories blurred (Martin \& White, 2005, p. 35). Martin and Rose (2003, p. 38) refer to this as 'turning the volume up or down'. The two resources which construe graduation are force and focus.

Force is resources used to alter the degree of evaluations to make them more or less intense. It comprise raise (e.g. cleaner, cleanest, enourmous, etc.), or lower (e.g. a bit, 
very few, the least bit, etc.). Evidence of force is linguistically realised in words with negative/positive meanings (e.g. metaphors), repetition and synonymy which affects the scaling of intensity, intensifiers and disjuncts (http://www.alvinleong.info/sfgappraisal. html). The 'force' of particular evaluations can thus be 'upscaled' or 'downscaled' (Bock, 2011, p. 7).

Focus is a resource used in the non-gradable context. It adjusts the 'strength of boundaries between categories, constructing core and peripheral types of things' (Martin \& White, 2005, p. 37). The concern of focus is with class-membership, or the grading of meanings in terms of how prototypical they are in a specific category or how weakly or strongly something fits into a particular class (http://www.alvinleong. info/sfgappraisal.html, Bock, 2011, p. 7).

\section{Example 5 \\ Male toilets $C$ \\ DESTROY APART \\ DESTROY RACE \\ DESTROY CAPITAL \\ DESTROY SEX \\ DESTROY HOMOPHOBIA}

It can either shapen (e.g. entirely secluded, etc.) or soften (e.g. kind of, somewhat, etc.) or grade the message from low to high intensity for effect (Bock, 2011, p. 7).

\section{Engagement}

The category of Engagement is concerned with the rhetorical potential of texts, how texts both function to explicitly persuade, and also to influence and contribute to the naturalisation of assumptions, beliefs, attitudes by more indirect, implicit means (http:// www.grammatics.com/apraisal/apraisaloutline/framed/AppraisalOutline-o8.htm). It involves identifying the 'particular dialogic positioning associated with given meanings and towards describing what is at stake when one meaning rather than another is employed' (Martin \& White, 2005, p. 97). Engagement thus entails the analysis of linguistic resources that explicitly position a text's propositions and proposals intersubjectively. It enables the writer to either distance or align himself/herself from what is written/spoken according to Voloshinov (1995, p. 139). Voloshinov, similar to Martin and White (2005), adds that Engagement is dialogic in nature, where the participant 'responds to something, affirms something, anticipates possible responses and objections, seeks support, and so on' (Voloshinov, 1995, p. 139). It consists of two components: monoglosia and heteroglosia. Monoglosia occurs when there are no references to other viewpoints. Heteroglossia, in turn, refers to when references to other viewpoints exist. Engagement is linguistically realised in the form of disclaiming (denials, counter arguments, etc.), proclamation, entertainment (e.g. probably, likely, etc.) and attribution (http://www.alvinleong.info/sfgappraisal.html).

Intersubjective and ideological convergence and divergence is evident in explicit values of attitude. The understanding of how the values of Graduation and Engagement 
might function to consolidate, disrupt or negotiate such convergence or divergence is pertinent (http://www.grammatics.com/apraisal/apraisaloutline/framed/AppraisalOutlineo8.htm).

\section{Resemiotisation and semiotic remediation}

When discussing resemiotisation, it becomes pertinent to define semiotics, as semiotics is the root of resemiotisation (Liu \& Makoni 2008, p. 1). Saussure defines semiotics as the 'study of signs as part of social life'. ${ }^{2}$ There are various semiotic systems that include non-verbal signs (for instance, colour, sound, image, gestures and so forth) as well as verbal signs (language based). When looking at resemiotisation, one would look at how these semiotic systems or material meanings transform one another (Iedema, 2003, p. 30; Liu \& Makoni, 2008, p. 2). Iedema notes that resemiotisation addresses the 'inevitably transformative dynamics of socially situated meaning-making processes' (Iedema, 2003, p. 30).

\section{Example 6 \\ Male toilets $A$ \\ WRONG! \\ God does exist ... \\ he just doesn't give \\ a fuck!! [affect/judgement, unhappiness, neg]}

Resemiotisation also deals with how textual meanings are transformed, shifted and reordered in multimodal entextualisations across practices and contexts (Silverstein \& Urban, 1996). As an analytical tool, it is used in this paper in the analysis of recontextualised semiotic material in toilet graffiti. Thus, at core of our focus is on how "materiality" ('expression') serves to realise the social, cultural and historical structures, investments and circumstances of our time (Iedema, 2003). In this way, 'resemiotization contributes to displacing analytical attention from discourse as structured meaning towards practice as material affordance' (Iedema, 2003, p. 50).

Resemiotisation therefore provides the analytical means to trace how semiotic material are translated from one mode into another as social processes unfold, as well as provide the means to question why certain semiotics are mobilised for certain functions at specific times as opposed to others (Iedema 2003, p. 29). However, our interest is also in how known texts and semiotic resources are made to do new things that they were not originally known for: hence our interest in a related notion of semiotic remediation, particularly the element of repurposing (Bolter \& Grusin, 1999). Drawing on semiotic remediation, our interest is in the multiple ways in which semiotic materials are re-voiced, re-ported, re-presented and reused (Prior \& Hengst, 2010) for new purposes on toilet walls as alternative media in which students express their evaluations.

Evidently, there are overlaps between the notions of resemiotisation and semiotic remediation in as far as they are designed to show how semiotic material are represented 
across modes, media and chains of mediation (cf. Iedema, 2003; Prior \& Hengst, 2010), and thus they can be used interchangeably. However, we use the notion of repurposing, which is derived from semiotic remediation, when we want to show how prior material in original or modified form is reused for new purposes in toilette graffiti.

In terms of multimodal analysis of the graffiti, we draw on the quadrants ('Given', 'New', 'Real', 'Ideal') proposed by Kress and van Leeuwen (1996). These will be used to refer to the spatial elements on toilet walls. The 'Given', which represents known, familiar information and 'New', which is regarded as the location for the new information, is separated by the vertical axis; whereas the horizontal axis give rise to the 'Ideal', which represents the idealised information and 'Real', which represents more factual information. We are aware of the limitations of using the quadrants considering the fact that the exact position of different elements is always changing as new elements are added or being removed. Moreover, the reference points are constantly changing and movements are not always from left to right. The spatial positionings are used more for referencing purposes than for their information value.

\title{
Research design and methodology
}

We purposefully selected male toilets, which are most often used by students on the UWC main campus. We also selected the most frequented toilets, as well as the toilets that had the most inscriptions. The locations in which these selected toilets were situated are referred to as toilets $\mathrm{A}-\mathrm{E}$ in the order in which they are named, for the ease of reference. A total of 10 toilets were selected for data collection.

\author{
Example 7 \\ Male toilets $B$ \\ The best thing you \\ can do as a young \\ man is to accept the \\ Lord Jesus Christ as your \\ personal saviour and \\ your life will never be the \\ same eternally \\ I was here drunk last \\ year in a besh but now \\ a'm heppily saving the Lord [affect, happiness, positive] \\ $4 \mathrm{u}$ a'so this is possible \\ with his grace
}

There were two periods of data collection, in a time frame of 8-10 months. The first period of data collection occurred from June 2008 to September 2008. The second period occurred from April 2009 to July 2009. The idea was to collect the data over a one-year period. Data were collected during hours when students' visits to the university toilets were minimal (early mornings and late evenings).The researchers made use of a digital camera to collect data. Data that could not be captured by the camera owing to faded colour was handwritten or video recorded. 
The writings often occurred in pencil, pens and felt-tipped pens. This means there were variations in terms of the font, size and nature of the data. The corpus of tokens is more than 1500 extracts. The large amount of data was meant to strengthen the dependability and representativity of the findings. However, we only use over 150 tokens of graffiti instances that capture the extended range of topics covered in the graffiti, which included issues on politics, race, economics, religion, culture and relationships.

In terms of number, the attitudinal instances collected in the first sample comprised $19.4 \%$ of the total instances and $80.6 \%$ in the second sample. The large increase in the number of tokens in the second sample is ascribed to developments in the social and political context in South Africa, as this was the period in which a new president was to be elected and when South Africa was plagued by xenophobic attacks. This opened the floor to engagements on topics such as politics, race, culture and religion. The first two topics accounted for over $80 \%$ of the data collected in sample 2 .

\section{Emotional expression of politics, race, culture and religion}

The most instances of emotional expression (affect) occur when men discuss politics and race. Participants did not only use lexicon to express their emotions but also made use of punctuation, capital letters, and transgressive images and verbal forms, such as verbal or pictorial insults used to raise the emotional effect. The following extracts include negative emotions falling into the unhappiness dimension of affect and will form the platform for the discussion which follows. In this section, we discuss how capitalisation, bold and underlining are used strategically to emphasise parts of the message, and to increase the emotional load of inscriptions.

In the first example of affect, Participant 1 takes a stance and apologises to the victims of the xenophobic attacks in South Africa, which started in May 2008 and spurred again in May 2009. Participant 1's response includes feelings of remorse and repentance, which are evident in the verbal phrase 'Saying Sorry'. The implicit moral anguish experienced by Participant 1 is thus categorised as unhappiness. The fact that the word 'Sorry' is capitalised as well as in bold indicates that the participant intentionally stressed the importance of these selections. Because this phrase forms part of the appraisal, it inevitably elevates the emotional weight of the inscription.

The admission of guilt and repentance of the past misdeed on behalf of the attackers, which is a positive deed performed by Participant 1, has opened the floor to negative engagement by Participant 2, since he responds by distancing himself and expressing his anger towards South Africans. This is also evident in his instance of denial 'NO' and presentation of a counter position of not forgiving South Africans for the xenophobic attacks. Participant 2 did not only direct his anger towards the South Africans involved in the xenophobic attacks, but to South Africans as a whole. He therefore places judgement and portrays animosity towards South Africans as a whole and constructs them all as being a part of the plot in the xenophobic attacks. Participant 2 uses capital letters as well as swearwords to express and emphasise his anger. 
The onset of Participant 2's response is the word 'NO', focusing the readers' attention on this foregrounded engagement which clearly states the participant's position in the matter of forgiving. It is not only in capital letters, but is also underlined to escalate the emotion and strengthen unwillingness to forgive. He portrays negative feelings of anger and constructs himself as unforgiving, which causes the readers to be positioned negatively towards him.

It is noteworthy to mention that although capitalisation is strategically used in some cases to strengthen the emotional load of inscriptions and to highlight particular aspects of the message, it does not always perform this functions is the case with 'behalF'and 'bRiGHT SiDE'. In these instances, the emotional load of the token is lighter and the participants introduced an element of play in their graffiti by displaying creativity and opened the floor to multiple inferences through the interplay of small letters and capitalisation of some letters. For instance, 'bRiGHT' can be interpreted as a play on bright/right. It is therefore essential to understand the choices and selections of participants within the context they occur.

Feelings about the South African president, Jacob Zuma, are also rich in emotive evaluation. The current South African president, Jacob Zuma, is intertextually referenced as $\mathrm{JZ}$ because of his initials. JZ is also the name of a renowned American rapper and music producer. This reference also sparked discourse on rap. The initials $\mathrm{JZ}$ are designed to capture the attention of the young men, who perhaps listen to rap music, and direct them to read the message, which in his case is about Jacob Zuma. The following extracts also indicate how capitalisation is used to stress the emotion in the inscription as well as to signal despondency.

In the extract above, feelings of despair and despondency are evident in Participant 1's reply about the current president, Jacob Zuma. Feelings of hopelessness are evident in the phrase 'NOW nothing we can do will change that'. This instance also reveals the participants stance towards the election of Jacob Zuma, which includes claims of solidarity in proclamation that his feelings are shared through use of 'we'. This form of engagement invited the response of participant 2 who aligned with the views of participant 1. Participant 2 wrote that he 'HATE JZ'. 'HATE' is a strong emotion of dislike. Participant 2 capitalised the entire token for emphasis and maximum emotional impact.

He thus constructs himself as an 'enemy' of the current South African president. Both participants draw on their political affiliation as not being supportive of the current South African president, Jacob Zuma. The word 'NOW' is strategically capitalised to indicate that the participant had been hopeful for a different president but now that Jacob Zuma had been chosen to be the president, nothing could be done. Both instances of affect relating to President Jacob Zuma involve the negative expression of emotions towards the president and the position he holds. This in turn constructs the president negatively as someone who is hated and not wanted as a president. On the other hand, 'JZ ONLY' suggests that JZ's colleagues in his party and government are positively evaluated. 
This inscription also gives an indication about the time in which this writing took place - just after the general election. The general election was held in late April 2009 and this sample was collected in April 2009. At this time, the ANC had already elected Jacob Zuma as its president, and since the ANC was expected to win the general election, it was a foregone conclusion that Jacob Zuma would become the president of South Africa.

Discussions on race and culture were not only prominent but also emotionally loaded. The following extracts show how exclamation marks and quotation marks are used creatively to emphasise linguistic choices and inevitably enhance the emotional weight of the inscriptions. In most of the racially charged inscriptions, people whom the emotions are targeted towards are not only specified, but they are classified in terms of their race. The extracts below are responses to an inscription which stated that 'coloureds' are 'racially' superior to 'blacks.'

The targets of Participant 1's evaluation are 'hotnots.' Parts of the word have been disguised by making use of asterisks $\left(^{*}\right)$. The irony is that the self-censorship through use asterisks only enhances the racial slur, as its use draws the reader to it and particularly to its masked venom. 'Hotnot' is 'A word used for coloured people in the Western Cape in South Africa, who have profound Khoisan ethnic facial features. It is considered by everyone to be a derogatory word and is not used in a normal, decent conversation'. ${ }^{3}$ This use of the term 'hotnot' is, however, not restricted to the Western Cape as it is often used to demean so-called mixed race people in South Africa generally. The lexicon used is therefore intentionally used to belittle the 'coloured' people. However, the use of quotations marks in one extract and an exclamation mark in another suggests there are two kinds of 'coloureds' who are being referred to. In addition to raising the emotional effects of the utterance, in the second extract, the participant made use of quotation marks to specifically highlight whom the text is directed towards in the context of this exchange. Inverted commas 'coloureds' limit specification to 'coloureds' such as the one who wrote that 'coloured' people are racially superior to blacks. Participant 3 uses the notion of 'coloured' in a more general but dismissive way. Inverted commas also suggest that the people who call themselves 'coloured' are not really 'coloured'. This is therefore done to decrease the credibility of the concept 'coloured', which is also reflected in Participant 3 discourse. Indeed one of the posts questioned the origins of the coloured people and judged them for not knowing about their origins.

An interesting occurrence takes place in the second extract, where punctuation is used to increase evaluation. This occurs where the second evaluators are the mothers of the coloured people. In this extract, the exclamation mark, which is usually placed at the end of a short sentence to express strong feelings, is placed in the middle of the sentence following the swear word 'fucken' and preceding the target of evaluation (coloureds') 'mother'. This is an unusual place in which to use the exclamation mark in the sentence but it has significance in terms of the meaning portrayed in the text. The punctuation mark in this instance functions to place emphasis on the swear word 'fucken'. It consequently loads the already loaded swearword and causes a climax before specifying the second evaluated person in extract 2, the mother. This raise in 
temper before the specification of the mother is made is interesting, since males are known to take great offence when their mothers are insulted. Participants therefore use swearwords and punctuation in creative ways as graduation forces to increase the emotional load in the feelings they express. It can also be argued that these words and punctuation devises are recontextualised from their grammatical contexts (for example to signal the beginning of a new sentence or proper nouns) and repurposed (Prior \& Hengst, 2010) to serve as appraisal resources in the data analysed, since they are not used in their usual context, but are employed to serve an evaluative function as is shown above.

In another instance of affect, punctuation and capital letters are used in combination with taboo language to enhance the emotions in the writing. The extract 'Fuck ALL U!!!' (Male toilets A), which is surrounded by political discourse and extracts of maleto-male sex advertisements, uses unconventional word order, punctuation and capital letters to enhance the anger in the utterance. In the above extract, not one but three exclamation marks are used to raise the emotional bar. In addition to the use of exclamation marks, the participant also uses capital letters selectively to place emphasis on certain elements in the sentence. In this instance, the capital letters are recontextualised from its syntactic 'positioning' and function and repurposed to place emphasis on the participants whom this anger is directed towards. This includes 'You'. The presence of the taboo language choice 'Fuck' raises the emotional bar in the text, which is then aided by the exclamation mark to load the emotional weight in the extract further. The word order, exclamation marks and the swearwords are used in this case to negatively finetune the evaluations and to indicate strong emotions of affect.

On the other hand, the extract 'Fuck you all' (Male toilets A) found near religious discourses does not contain a strong sense of emotion, as in the case of the previous extract. It can be classified as negative affect illustrating anger but the patterned use of capital letters (starting with capital letter and continuing with small letters) and conventional word order lessen the emotional weight of the affect. The use of conventional punctuation also causes this inscription to be less loaded and threatening than the one previously discussed. In short, word order capitalization and punctuation marks are used in these cases as grammatical intonations of evaluations.

There are also random instances of affect that occur in the data, largely in response to existing toilet graffiti. In one of these examples, the participant swears at the initial participant and calls him an 'ASSHOLE' (Male toilets A), which indicates that he is not just angry, but really extremely angry and offended by the initial participant. In this example, capital letters are also recontextualised to enhance the emotional load of the utterance. This utterance is in response to graffiti which read 'small dick boy' (Male toilets A).

\section{Judging prejudice, judging religion}

Many of the judgements found in the data are in response to existing writings on the toilet walls. The data suggest that most of the tokens coded as instances of judgement are in capital letters as opposed to the rest. Below are examples of these. 
Participant 1 constructs black and coloured communities as nations that cannot create anything. These "nations" are constructed as unaccomplished and useless, who only write on toilet walls. In terms of their capabilities, the people belonging to these 'racial' groups are consequently unproductive and unaccomplished. Participant 1 therefore negatively constructs these 'racial' groups. This instance invites responses to which participant 2 aligns with the views of participant1. Participant 2 responds to this writing and positively affirms the truth-value of the views of Participant 1. Participant 3 does not state whether he agrees or not with Participant 1, but responds to Participant 1's writing by judging him on the basis that he judges the coloured and black populations as being unproductive because they write on toilet walls, yet he is also guilty of the act of writing on toilet walls and hence of not being productive. Participant 3 therefore negatively evaluates Participant 1's action on the level of moral reprimanding on the basis that he is guilty of the same actions of which he accuses coloured and blacks. In essence, he is not in a position to judge them. Participant 3's response to Participant 1's inscription positions the audience negatively towards Participant 1.The use of capital letters by Participant 2 as well as ending off with an exclamation mark makes the text more visible and loads the weight of the emotions. Participant 3 also employs capital letters creatively in his response, he does this selectively to emphasise particular parts of the message, the subject and the action, which highlights the irony in participant 3's response.

The use of capitalisation to highlight and enhance emotionally loaded topics is succinctly captured in the extract below.

The writers strategically deploys capitalisation to charge the already emotionally loaded topics relating to apartheid, sex-/gender- and race-based discrimination, and homophobia. The capitalisation raises the emotional bar in the inscriptions. Consider, also, the extract below which a response to someone who wrote that God does not exist.

Evidence of engagement exists in the form of a proclamation in the above instance 'God does exist'. The extract is double coded as affect and judgement, since implicit anger is portrayed as well as judging God. This anger is signalled by the presence of the exclamation marks, as well as by considering the meaning of the sentence. This participant is unhappy with the state of affairs and expresses his anger and frustration as, for him even though He exists God does not care (about people's suffering?). In this example, the participant used capitalisation to emphasise his stance - that God does not care. His inscription is further loaded by the use of multiple exclamation marks as well as the selection of the swear word 'fuck'. Because of these selections, one is to infer that this inscription falls within the unhappiness dimension of affect, as well as judgement that is directed towards God. However, the extract below illustrates positively evaluated feelings towards God and Jesus.

In the above extract, the male participant explicitly expresses his happiness in his writings in the phrase 'a'm heppily saving the Lord'. Indications of security are also found for the participant is secure in trusting God and accepting Him as personal savior 'best thing you can do as a young man' as well as satisfaction, since the extract indicates 
that he has reached a goal in his life. The participant indicates progression by highlighting the negative space in his life before accepting Jesus in his life, then indicating the change with the word 'but' and the reassurance 'your life will never be the same eternally'. The above extract is rich in emotional content, although most of the emotions are implicitly realised in the context of the extract. This text positions the readers positively toward the participant's experiences since the participant's growth is designed to be inspirational.

In another instance of affect found in male graffiti there is an extract which reads 'to flush devine' (Male toilets D), where one participant positively evaluates the process of flushing as a divine feeling, a feeling which comes from God. The above example could be argued to be appreciation, the evaluation of flushing, which would then be positively evaluated in terms of the participant's reaction since he enjoys the process of flushing.

\section{Multimodal appraisal resources}

As already implied elsewhere, evaluations achieved through verbal language are further enhanced multimodally through a play on phonetics/phonology and graphetics/graphology. The data in the male toilets indicates how language and image work together, that is, the process where various semiotics are appropriated for effective meaning-making in the limiting spaces of a toilet cubicle. The spatial together with temporal (one cannot stay in a toilet for hours without arousing attention/suspicion) limitation entails creative use of available semiotic material to enable the graffiti artist to make a range of meanings visible in evaluative 'discourses'. The picture below consists of an image of what appears to be voodoo with a broom in his hands. Participant 2 responds to this picture with his own image, a drawing of a stickman who farts on the voodoo. This is realised with the image as well as the word 'POOF' and inscription 'STICKMAN FARTS ON VOODOO'. This picture will serve as a referent for explaining how pictures are used together with lexico grammar to realise evaluative functions.

Evaluation in the form of judgement and engagement exists in the picture above, in which the participant drew a stickman who farts next to a picture of a voodoo and wrote 'stickman farts on voodoo!'. The conversational flow of these inscriptions is from the 'new' to the 'given' (according to the framework for reading images by Kress \& Van Leeuwen, 1996). This is evident in the nature of the interaction. In ordinary discourse a stickman is supposed to be a 'buddy', someone you appreciate and who appreciates you. However, the illustration of the stickman farting on the voodoo indicates the negative attitudes of the participant towards the picture of the voodoo drawing in terms of its composition. The notion of stickman is thus given new meaning. Remediation occurs in this communicative event, since the inscription 'poof' which is in the 'given' position is re-purposed and remediated in the 'new' positioning of the picture, as the meaning of the inscription has changed and is mediated by the 'new' context. In the 'new' positioning, the 'poof' serves as negative evaluation of the picture drawn as well as the concept of the voodoo (appreciation), whereas in the 'new' positioning, the 'poof' serves as a reference, since it indicates who the inscription is directed towards in addition to its evaluative function. The evaluation of the picture of 
the voodoo positions the reader negatively towards the picture itself as well as towards the message in the picture presented because of the mocking of the picture by Participant 2, who drew a stickman farting in response to the picture. This pictorial illustration supports Chalmers's view that 'visual symbols convey ideas and express emotions, qualities, and feelings.' (Chalmers,1981, p. 6). Below we develop this argument further by considering an image which captures the interaction between 3 participants. Participant 1 drew a picture of a paw, the number 28 and the sun, the latter being the symbol for one the most notorious gangs in Cape Town. This is responded to by Participant 2 with 'STOP WRITING KAK YOU'VE NEVER BEEN THER "FRANS SE VOOL" [STOP WRITING SHIT YOU HAVE NEVER BEEN THERE "FRANS" PENIS']. Participant 3 responds to Participant 1 with "TELL SMILEY I SAY HIS MA [MOTHER'S] SE POES [VAGINA]! IS HE STILL SMILING NOW?

Pictures are used with the written inscriptions to specify the receivers or the references of inscriptions as the above picture indicates. In gang-related inscriptions, the fact that the participant identifies with or relates a response to a particular gang as in the case of the inscription above raises the emotional bar and provides an avenue for other inscriptions. In South African, especially in the Western Cape Province, apart from tattoos, flags, secret language and other symbols such as salute, gangs are differentiated by their number. The $28 \mathrm{~s}$ are a gang that are said to specialise in rape and operate at night (Buthelezi, 2013). The responses surrounding 28 are written by someone familiar with the language and symbols associated with the $28 \mathrm{~s}$ gang. In the 28s language 'Frans' refers to a non-gang member and their thumb and the first two fingers salute is accompanied by reference to addressee's mother's genitals (Buthelezi, 2013). In Picture 2, we see the reference to 'HIS MA SE POES' in Afrikaans, meaning his mother's genitals. We could say that whoever wrote 28 is first described as a fake member who has never been there (in prison or is not a 28 gang member); while the second inscription is written with irony indirectly insulting the first writer's mother. But again the identities of the writers are not very evident and the message appears unclear but it may as well mean something to those initiated in gang language. What we can say for certain is that whoever wrote 28 is evaluated negatively and the references to 'Frans' and his mother's genitals serve to aggravate the appraisal.

The picture below comprise an image of a cartoon, with the response 'You Vacuous, ToFFey-nosed, Malderous Pervert!' which is responded to with the image of a closed hand with the middle finger that is raised.

In the above multimodal evaluative token, we find an instance of judgement in which one participant responds to the drawing of another and judges the other's behaviour as immoral by calling him a 'pervert' in 'You Vacuous, ToFFey-nosed, Malderous Pervert!'. Both the picture and the hand serve as semiotic elements to recreate the written message, as well as the anger inherent in the written words. The drawing of the face re-enacts the person as 'Vacuous, ToFFey-nosed' by making reference to the facial expression in the drawing. In the real position of the picture, the hand with the swearing sign re-enact the anger in the inscription. These pictures and the accompanying text are regarded as communicative stages of the 'communicative event' 
because they were the only inscription on the wall (besides the inscription at top of the ideal position of the picture), thus eliminating other options.

In the picture above, Participant 1 writes 'Shitology 111. To crap is animal. To wipe human. To flush devine!'. In the Real position of this picture occurs a response in the form of a stickman who is pointing a middle finger towards the inscription with the accompanying words 'Fuck you ...'. On the New quadrant of the picture is the image of a fat male named 'KURT' who is observing a well build couple, the male responding to him with the words 'THATS Y I FUCKED YOUR BITCH U FAT MOTHAFOCKA!'.

In this instance, Participant 1 creates a module entitled 'Shitology 111' and judges crapping as animal, therefore negatively evaluating it; wiping as human thus neutrally evaluating the act of defecating; and the act of flushing he describes as divine, thus evaluating it positively (see above for description). Evidence of graduation is inherent in this extract, since a gradual increase in evaluation occurs from 'animal' to 'human' to 'divine', the highest form of divinity, which is received from God. This form of graduation is also elevated with the use of the exclamation mark.

The evaluation itself and the function of the exclamation mark in this evaluation is not the only remarkable element within this inscription. The name of the 'module' itself is to be noted - 'Shitology 111'. This participant signals his identity as a student, by terming the Shitology module Shitology 111, which resembles the module names used in higher education. An aspect of academic discourse is therefore repurposed in the toilet graffiti to refer to (the study of) toilet etiquette. At least one reader is unimpressed with this 'creativity.'

In the above instance, the participant drew on external voices in the form of English poet Alexander Pope's widely referred to words 'To err is human, to forgive divine' from his 'Essay on criticism'. He did not only 'borrow' from this text but creatively changed and repurposed it for toilet humour and new meaning to suite the context of toilet.

When one considers the response to the inscription, in the 'Real' position, the picture can be said to add meaning to the words in the speaking bubble, and hence enhance evaluative force. This picture consists of a stickman who responds, 'Fuck you ...' to the inscription and module presented; therefore, it can be regarded as a negative evaluation of appreciation. Moreover, considering the juxtaposing of the two sets of inscriptions we could say that the multimodal negative evaluation in the iconic picture named 'Kurt,' in the 'New' position of the picture may also be in reference to the one who wrote 'Shitology.' In this event, 'Kurt' is constructed as obese, which is different to the inscriber, who constructs himself as muscular and having a partner, whilst Kurt remains the overweight onlooker. This is done through the use of iconic signs. The verbal signs emphasise this evaluation with ' $u$ fat mothafocka!' which negatively constructs Kurt.

From the discussion above, the purposive nature of toilette graffiti is quite obvious to extent that it can be said to be a genre. 


\section{Graffiti as a genre}

Graffiti has been termed a literary 'genre' by a number of scholars (Adams \& Winters, 1997; Barton \& Hamilton, 1998; Blume, 1985; Ferris, 2010; Lynn \& Lea, 2005; Pennycook, 2007 etc.). Martin defines genre as 'a staged, goal-orientated, purposeful activity in which speakers engage as members of our culture' (Martin, 1984, p. 25). Eggins (2004), in turn, describes genre as 'cultural purpose' of texts, thus social activity types in culture (Eggins, 2004, pp. 54-56).

From the definition of genre offered by Martin (1984), one can infer that a genre consists of communicational stages in which the purpose of the genre is realised. These stages refer to the organization of the text and are also known as the schematic structure of the text (Eggins, 2004, p. 59). The generic structure in toilet graffiti does not follow the structure of conventional genres, which are characterised by linear stages that are coherent in structure. Toilet graffiti as illustrated above has multidimensional reading paths and is multimodal, since it often consists of both verbal and non-verbal texts. As we demonstrated, in these multidimensional stages, a participant can add graffiti at any stage, often creating a different stage, in any direction, offering multiple reading paths. Each token that is added can be regarded as an additional stage or an elaboration of an existing stage. These additions are largely dependent on the availability of space and can be added at any point in the interaction.

It clear from the discussion above that toilet graffiti can also be said to be a recognisable, purposeful activity, which is goal-orientated (Bhatia, 1993; Martin, 1984). As is the case with other genres, toilet graffiti have a set of communicative purposes. If toilet graffiti is regarded as a recognisable event, users will recognise it as such and respond to it as a purposeful event. The most salient communicative purpose of the toilet walls where graffiti is created is to provide audiences with safe spaces for writing graffiti and expressing ideas that are often frowned upon in society, since the content of the graffiti often contains taboo or sensitive topics. Kaschula and Antonissen (1995) refer to taboos as 'words that may not be uttered and to topics that may not publicly be discussed' (Kaschula \& Antonissen, 1995, p. 24). These taboo words, topics as well as practices, are forbidden in communities, owing to moral, religious, cultural and social norms that are transgressed. One of the most salient functions of the toilet environment is therefore to create a home for these taboo topics to be discussed and practiced openly through graffiti.

The communities of users of genres often exploit the allowable contributions in the specific genres (Bhatia, 1993). This can be in the form of 'borrowings' from other genres, which are often cleverly and humorously remodelled in new contexts of the toilet. The borrowings result in multiple purposes and reference points. The multiple reference points can also be said to result in the structure of toilet graffiti not to follow a linear progression argumentation as in other genres. Multiple purposes may reflect multiple authorship, which may also explain the different paths in which the interaction flows, thus, staged multidimensional flow. 


\section{Conclusion}

The data indicate that the participants use creative strategies to enhance the emotional effects in their inscriptions and to position themselves and others. Among the tools used for emotional emphasis are punctuation (e.g. exclamation marks and quotation marks), taboo language and the selective use of capital letters which are repurposed to emphasise certain elements in the sentence and thus aid appraisal resources. The data also indicate the strategic selection of the semiotic resources had an effect on the meaning making and evaluative functions of the inscriptions.

We showed how graffiti artists use pictures as evaluative resources to aid the appraisals contained in the written message. They are also often used on their own to act as pictorial evaluative meaning-makers. In the sense that pictures, like verbal language, communicate meaning, we argue that strategically crafted images can also encode evaluative meaning. In this instance, the iconic sign as the picture can also be interpreted as a social sign. With regard to pictures and the interpersonal dimension, the sign and its referent are not obvious but the use of multimodality offers multiple frames for interpretation. Multimodal discourse analysis of toilette graffiti, at the very least, shows that images/visual resources work together with language to express particular meanings, and that they can express meanings by themselves: e.g. in the stickman cartoon.

We have shown how the images and verbal components are combined to construct and transform meaning in the new contexts through manipulating the emotional and evaluative load by use of punctuation, capitalisation, linguistic forms (including taboo language), images and sketches. Evidently, to arrive at the meaning one necessarily has to take into account images and verbal components that constitute the message. Since some of verbal and visual components are repurposed from prior texts and experiences, to arrive at a comprehensive evaluation of the appraisals, one has to look outside the toilet for intertextual meanings that have been reconstructed in the new contexts.

However, the meanings should be context specific since the manipulated semiotic material is made to do new things that they were not originally known for. It can be argued that the semiotic material is re-created and re-voiced (Bolter \& Grusin, 2009; Prior \& Hengst, 2010) on a toilette wall. The toilet wall thus provides an alternative media and context in which semiotic material is reused and transformed for novel meanings. The secretive and personalised nature of a toilet and the use of the material affordance of a toilet wall as an alternative mode or media are themselves transformative. Behind the toilet wall students write on topics and use the kind of language they would not normally use in everyday conversation or conventional written media such as a daily newspaper. This seems to spur the creative juices of the students who try to outsmart each other in terms use of words, images, graphics and other devices to get their messages across.

In short, the paper showed material affordances engendered by toilet walls and how these nurture novel meanings and become critical in unravelling the mobility of semiotic material in different forms across contexts and practices. Multimodality thus becomes a multifaceted process situated in the social context (Liu \& Makoni, 2008). 
Because of this socially situatedness of texts, the paper has shown that employing the notion of repurposing enabled us to go beyond mere analysing the complexity of the multimodal nature of texts and representations, to also explain how these texts or semiotic representations were (re)formulated in the first place, and critically, how these (re)-formulations lead to novel situated meanings. In terms of Appraisal theory, we want to argue that in meaning-making the verbal and non-verbal semiotic works together to engender novel evaluations. At the very least images and other multimodal resources serve as graduation tools to finetune evaluations and associated meanings.

In addition, we have shown that toilet graffiti should be recognised as a genre, regardless of the fact that it does not have a linear generic structure in terms of its communicational stages like other genres. It is a recognisable communicative event in the sense proposed by Bhatia (1993), as that its users recognise it as such and respond to it as a communicative event.

\section{Acknowledgement}

Any opinion, findings and conclusions or recommendations expressed in this material are those of the authors and therefore the NRF does not accept any liability in regard thereto.

\section{Disclosure statement}

No potential conflict of interest was reported by the authors.

\section{Funding}

This work was supported by the National Research Foundation.

\section{Notes}

1. http://www.grammatics.com/appraisal/AppraisalOutline/Framed/Frame.htm (accessed January 2014).

2. Chandler, D. Semiotics for Beginners. Available online: http://www.aber.ac.uk/media/Docu ments/S4B/semiotic.html (accessed 26 January 2014).

3. http://www.urbandictionary.com/define.php?term=hotnot. 


\section{References}

Adams, K. L., \& Winter, A. (1997). Gang graffiti as a discourse genre. Journal of Sociolinguistics, $1,337-360$.

Barton, D., \& Hamilton, M. (1998). Local literacies: Reading and writing in one community. London: Routledge.

Bates, A. J., \& Martin, M. (1980). The thematic content of graffiti as a nonreactive indicator of male and female attitudes. The Journal of Sex Research, 16, 300-315.

Bhatia, V. K. (1993). Analysing genre: Language use in professional settings. London: Longman.

Blume, R. (1985). Graffiti. In T. A. van Dijk (Ed.), Discourse and literature: New approaches to the analysis of literary genres (Vol. 3, pp. 137-148). Amsterdam: John Benjamins.

Bock, Z. (2007). A discourse analysis of selected truth and reconciliation commission testimonies: Appraisal and genre (Unpublished PhD thesis). University of the Western Cape, Bellville.

Bock, Z. (2011). Code-switching: An appraisal resource in TRC testimonies. Functions of Language, 18, 183-209.

Bolter, J., \& Grusin, R. (1999). Remediation: Understanding new media. Cambridge, MA: MIT Press.

Buthelezi, T. (2013). South African prisons - gang dynamics and brotherhood *numbers gang*. Retrieved from

http://thembatimss86buthelezi.wordpress.com/2013/12/09/south-africanprisons-gang-dynamics-and-brotherhood-numbers-gang/

Chalmers, F. G. (1981). Art education as ethnology. Studies in Art Education, 22, 6-14.

Cooper, D., \& Subotsky, G. (2001). The skewed revolution, trends in South African higher education: 1988-1998. Cape Town: Education Policy Unit, University of the Western Cape.

Dundes, A. (1966). Here I sit - a study of American latrinalia. Kroeber Anthropological Society Papers, 34, 91-105.

Economou, D. (2009). Photos in the news: Appraisal analysis of visual semiosis and verbal-visual intersemiosis (PhD dissertation). University of Sydney, Department of Linguistics, NSW, Australia.

Eggins, S. (2004). An introduction to systemic functional linguistics. London: Continuum International Publishing Group.

Eggins, S., \& Slade, D. (1997). Analysing casual conversation. London: Cassel.

Farr, J. H., \& Gordon, C. A. (1975). A partial replication of Kinsey's graffiti study. The Journal of Sex Research, 11, 158-162.

Farnia, M. (2014). A thematic analysis of graffiti on the university classroom walls - A case of Iran, International Journal of Applied Linguistics \& English Literature, 3, 48-57.

Ferris, F. S. (2010). Appraisal, identity and gendered discourse in toilet graffiti: A study in transgressive semiotics (Unpublished masters dissertation). University of the Western Cape, Bellville.

Flores, L., \& Sechrest, L. (1969). Homosexuality in the Philippines and the United States: The handwriting on the wall. The Journal of Social Psychology, 79, 3-12.

Gebhard, P. H., Kinsey, S., Martin, C. E., \& Pomeroy, W. B. (1953). Sexual behavior in the human female. Philadelphia, PA: Saunders. 
Green, J. A. (2003). The writing on the stall: Gender and graffiti. Journal of Language and Social Psychology, 22, 282-296..

Iedema, R. (2003). Multimodality, resemiotization: Extending the analysis of discourse as a multi-semiotic practice. Visual Communication, 2, 29-57.

Iedema, R., Feez, S., \& White, P. (1994). Stage two: Media literacy. A report for the Write it Right Literacy in Industry Research Project by the Disadvantaged Schools Program. New South Wales: Department of School Education.

Jewitt, C., \& Kress, G. (Eds.). (2003). Multimodal literacy. New York, NY: Peter Lang. Kaschula, H. R. \& Anthonissen, C. (1995). Communication across cultures in South Africa: Towards critical language awareness. Johannesburg: Hodder \& Stroughton and Witwatersrand University Press.

Kress, G. R. (2010). Multimodality: A social semiotic approach to contemporary communication. London: Routledge.

Kress, G. R., \& van Leeuwen, T. (1996). Reading images: The grammar of visual design. London: Routledge.

Lalu, R., \& Murray, N. (Eds.). (2012). Becoming UWC: Reflections, pathways and unmaking apartheid's legacy. Bellville: UWC Centre for Humanities Research.

Liu, L. X., \& Makoni, S. B. (2008). Gain and loss of meaning in the process of resemiotization: A critical study of one clip from Grey's anatomy. Retrieved from www.scribd.com/doc/ 30147601/APLNG-482Final-Paper

Lomas, H. D. (1973). Graffiti: Some observations and speculations. The Psychoanalytic Review, 60, 71-89.

Lynn, N., \& Lea, S. J. (2005). "Racist” graffiti: Text, context and social comment. Visual Communication, 4, 39-63.

Martin, J. R. (1984). Language, register and genre. In F. Christie (Ed.), Children writing: A reader (pp. 21-30). Geelong: Deakin University Press.

Martin, J. R., \& Rose, D. (2003). Working with discourse: Meaning beyond the clause. London: Continuum.

Martin, J. R., \& White, P. R. R. (2005). The language of evaluation. New York, NY: Palgrave. Olowu, A. A. (1983). Graffiti here and there. Psychology Reports, 52, 986.

Pennebaker, J. W., \& Sanders, D. Y. (1976). American graffiti: Effects of authority and reactance arousal. Personality Social Psychology Bulletin, 2, 264-267.

Pennycook, A. (2007). Global englishes and transcultural flows. London: Routledge.

Pennycook, A. (2008). Linguistic landscape and the transgressive semiotics of graffiti. In E. Shohamy \& D. Gorter (Eds.), Linguistic landscapes: Expanding the scenery (pp. 302-312). New York, NY: Routledge.

Prior, P. A., \& Hengst, J. A. (Eds.). (2010). Exploring semiotic remediation as discourse practice. New York, NY: Palgrave.

Silverstein, M., \& Urban, G. (1996). Natural histories of discourse. Chicago, IL: University of Chicago Press.

Vandenbergen, A. (2008). Appraisal theory: A short introduction (Unpublished paper). Linguistics Department, University of Ghent, Ghent.

Voloshinov, V. N. (1995). Marxism and the philosophy of language, Bakhtinian thought - An introductory reader. (S. Dentith, L. Majoka, \& R. Titunik, Trans.). London: Routledge. 
Wales, E. \& Brewer, B. (1976). Graffiti in the 1970s. Journal of Social Psychology, 19, 115-123.

Wolff, B. (2010). The writing on the stall: Graffiti, vandalism, and social expression," Kaleidoscope, 9, Article 11. Retrieved from http://uknowledge.uky.edu/kaleidoscope/vol9/iss1/11

Wolpe, H. (1995). The debate on university transformation in South Africa: The case of the University of the Western Cape. Comparative Education, 31, 275-292.

\section{Online sources}

http:www.alvinleong.info/sfgappraisal.html

http:www.alvinleong.info/sfgappraisal.html 